\title{
Assessment of socio-demographic and clinical factors associated with preeclampsia and eclampsia among primigravida attending tertiary care center in South India
}

\author{
Rency M. Jaboi*, Vahitha S., Nivedita
}

Department of Obstetrics and Gynecology College of Nursing, Jawaharlal Institute of Postgraduate Medical Education and Research, Puducherry, India

Received: 14 August 2020

Accepted: 21 September 2020

*Correspondence:

Rency M. Jaboi,

E-mail: rencyjaboi@gmail.com

Copyright: (c) the author(s), publisher and licensee Medip Academy. This is an open-access article distributed under the terms of the Creative Commons Attribution Non-Commercial License, which permits unrestricted non-commercial use, distribution, and reproduction in any medium, provided the original work is properly cited.

\section{ABSTRACT}

Background: The objective of the study was to identify the socio demographic and clinical factors associated with preeclampsia and eclampsia among primigravida attending a tertiary care center in South India.

Methods: A quantitative research approach with case control design was used. Non-probability convenience sampling was used to select two groups of primigravida mothers i.e. one group with 108 mothers having preeclampsia or eclampsia and one group with 108 mothers not having preeclampsia or eclampsia. A structured questionnaire was employed to collect the data.

Results: The study found that preeclampsia and eclampsia was significantly associated with maternal age $(p=0.026)$, hemoglobin level $(p=0.003)$, body mass index $(p=0.001)$, weeks of gestation $(p=0.016)$, age at menarche $(p=0.003)$, age at first pregnancy $(\mathrm{p}=0.007)$, nutritional education $(\mathrm{p}=0.001)$, history of thyroid disorder $(\mathrm{p}=0.025)$, family history of hypertension $(\mathrm{p}=0.016)$, salt consumption $(\mathrm{p}=0.001)$, consumption of fried fatty food $(\mathrm{p}=0.008)$ and processed $\operatorname{sugar}(\mathrm{p}=0.045)$, and intake of green leafy vegetables $(\mathrm{p}=0.001)$, pulses and beans $(\mathrm{p}=0.031)$ and activity $(\mathrm{p}=0.015)$. In the multiple regression analysis, body mass index (Adjusted Odds Ratio [OR] 2.28 [1.40-3.71] p=0.001), thyroid disorder (adjusted OR 2.756 [1.135-6.645] p=0.025) and intake of green leafy vegetables (adjusted OR 1.69 [1.223$2.360] \mathrm{p}=0.002$ ) were found to be independent risk factors associated with preeclampsia and eclampsia.

Conclusion: The study concluded that the risk factors should be identified and evaluated during the antenatal visits for early detection so as to reduce maternal and neonatal mortality.

Keywords: Preeclampsia, Eclampsia, Primigravida, Clinical factors, Multiple logistic regression

\section{INTRODUCTION}

Pregnancy is a joyful experience of a woman's life and she undergoes exaggerated physiological responses and hormonal disarray which may lead to complications in pregnancy. Some pregnancies end tragically with maternal and neonatal morbidity and mortality. More than one and half million women suffer from pregnancy related complications every year. ${ }^{1,2}$ One such complication which occurs in the second trimester is preeclampsia and eclampsia which leads to approximately one third of total maternal deaths worldwide. Preeclampsia and eclampsia (PE) are two of the hypertensive disorders of pregnancy that has become a significant public health risk in both the developed and developing countries contributing to maternal and perinatal mortality and morbidity. ${ }^{3}$ The incidence was estimated to be between 3 and $10 \%$ of all pregnancies. ${ }^{4}$

Preeclampsia is a disorder of unknown etiology which affects multiple systems and is categorized by the development of blood pressure of $140 / 90 \mathrm{~mm} \mathrm{hg}$ or more 
with presence of protein in urine in a woman who was previously normotensive and non-proteinuric after $20^{\text {th }}$ week of gestation. Eclampsia refers to the manifestation of generalized tonic-clonic seizures or occurrence of coma in women with preeclampsia. ${ }^{5}$ They are associated with intrauterine growth retardation, preterm birth, maternal and perinatal morbidity and death.

World health organization reports 70,000 cases of maternal morbidity and mortality occurred due to preeclampsia every year worldwide. $^{6}$ In a study conducted among the population of India, the prevalence of hypertensive disorders was found to be $7.8 \%$ and preeclampsia $5.4 \%$ respectively. ${ }^{7,8}$ Over the years, the studies reveal that the prevalence of preeclampsia and eclampsia ranges from $33 \%$ (Haryana) to $87.5 \%$ (Tripura) in India. The prevalence of preeclampsia in South India was Andhra Pradesh (36.4\%), Karnataka (37.3\%), Kerala $(77.1 \%)$ and Tamil Nadu (48.1\%). In Puducherry $6.2 \%$ pregnancy induced hypertensive cases detected at institution and $0.2 \%$ eclampsia cases. ${ }^{9}$

It is often referred to as 'Disease of theories' because the causes and risk factors for the same remain unclear. ${ }^{10}$ Diabetes, obesity, multiple pregnancy, primiparity, personal or family history of preeclampsia and chronic hypertension are some of the factors which are thought to increase the risk to preeclampsia. ${ }^{11-13}$ In another study which was conducted in Karnataka, pre-pregnancy body mass index, history of chronic hypertension, diabetes, renal disease, family history of hypertension and history of preeclampsia in earlier pregnancy were some of the risk factors that were identified. ${ }^{14}$

Since the etiology remains unclear in spite of several efforts to find potential risk and perinatal and postnatal outcome associated with preeclampsia and eclampsia is not good, so early detection and prevention is the key to reduce maternal and neonatal morbidity and mortality. Proper and timely antenatal care remains imperative part of prevention. Determining these risk factors in antenatal period will help in identifying the high-risk women and in providing them with prompt treatment and thus, reducing maternal morbidity and mortality.

Therefore, the study was conducted to evaluate clinical factors of preeclampsia and eclampsia among primigravida for early detection so as to reduce maternal as well as neonatal morbidity and mortality.

Objectives of the study were to identify sociodemographic and clinical factors associated with preeclampsia and eclampsia among primigravida attending a tertiary health care hospital in South India and to find out the association between socio-demographic and clinical factors associated with preeclampsia and eclampsia among primigravida attending a tertiary health care hospital in South India.

\section{METHODS}

This was a case control study conducted from August 2019 to October 2019 at Women and children hospital, Jawaharlal institute of postgraduate medical education and research, Puducherry, India. Ethical committee clearance was obtained from institutional ethics committee (JIP/CON/2019/033). The data was collected after getting permission from head of the department and study participants. The primigravida attending antenatal OPD, eclampsia ward, high dependency unit and antenatal ward in WCH, JIPMER were included in the study. The questionnaire was validated by experts. Informed consent was taken. Through socio-demographic proforma basic demographic variables was collected from the primigravida. Through structured questionnaire the clinical factors of preeclampsia and eclampsia was collected.

\section{Subject's characteristics}

Case: Primigravida diagnosed with preeclampsia or eclampsia attending eclampsia room, high dependency unit and antenatal ward in WCH, JIPMER.

Control: Primigravida without preeclampsia or eclampsia attending antenatal OPD, WCH two groups of primigravida mothers available during data collection were included as per inclusion and exclusion criteria. Pregnant women with pre-existing co-morbidities like chronic hypertension were not included in the study.

Inclusion criteria included antenatal women with a gestational age of 20 weeks or more, who were pregnant for first time and who were willing to participate.

Exclusion criteria excluded women already diagnosed with chronic hypertension, women having pre-existing obstetrical co-morbidities.

\section{Variable selection}

Demographic variables include maternal age, domicile, educational status, employment status, type of marriage, type of family and monthly income. Clinical factors include BMI, blood group, hemoglobin level, weeks of gestation, age at menarche in years, antenatal visit and consultation, nutritional education given, folic acid intake, placental complications, type of conception, thyroid disorder, connective tissue disorder, renal disease, diabetes, family history of hypertension, family history of diabetes, activity, tobacco use, alcohol use and dietary factors like salt consumption, fatty fried food and processed sugar consumption, intake of milk, green leafy vegetables, fish, pulses and beans .

\section{Statistical analysis}

Statistical package for social sciences (SPSS) for windows version 23.0 was used. The distribution of 
categorical variables such as education, educational status, type of marriage, type of family, co-morbidity, antenatal visit and consultation was expressed in terms of frequency, percentage, proportion and odds ratio with 95\% confidence interval. Chi-square was used to compare proportion between the groups. The continuous variables such as age at marriage, age at pregnancy, gestational age and BMI was expressed in terms of mean. Independent student's $t$ test was used for comparing mean between the data. Multiple logical regression analysis was used to identify the clinical factors associated with preeclampsia or eclampsia. All the statistical analysis was carried out at $5 \%$ level of significance with $\mathrm{p}<0.05$.

\section{RESULTS}

The data collected showed that majority of the women in the group with case $(72.2 \%)$ and in control group (84.3\%) were between 19 and 30 years of age. Majority of the women in the case group and in control group that is $66.7 \%$ belonged to the rural area. $40.7 \%$ of the women in the case group and $33.3 \%$ in the control group were graduates. Most of the women in the case group (93.5\%) and in the control group $(95.4 \%)$ were unemployed. The data collected showed that majority of subjects in the case group $(71.3 \%)$ and in the control group (66.7\%) had non-consanguineous marriage. $56.5 \%$ of the women in the case group lived in the nuclear family as compared to the control group in which majority $(50.9 \%)$ lived in a joint family. Majority of the women in the case group $(42.6 \%)$ and in the control group $(40.7 \%)$ had monthly income of less than 2000 .

Most of the subjects in the case group (38\%) were found to be overweight whereas in the control group majority of them $(49.1 \%)$ had normal body mass index. Most of the women in the case group $(96.3 \%)$ and in the control group (94.4\%) were $\mathrm{Rh}$ positive. Majority of the women in the case group $(66.7 \%)$ and in the control group $(57.4 \%)$ had normal hemoglobin level. Majority of the women in the case group $(74.1 \%)$ and in the control group $(87 \%)$ were less than 37 weeks of gestation. Majority of the women in the case group (54.6\%) and in the control group $(65.7 \%)$ were of more than 13 years of age at menarche. In case group, majority (52.8\%) belonged to more than 25 years at first pregnancy whereas control group, most of them $(47.2 \%)$ belonged to 21-25 years. Most of the women in the case group $(81.5 \%)$ and in the control group $(89.8 \%)$ took folic acid supplementation. Majority of the women in the case group (96.3\%) and in the control group (94.4\%) did not have any placental complications. Most of the women in the case group (85.2\%) and in the control group (95.4\%) had spontaneous conception. Women in the case group and in the control group had more than 4 antenatal visits $(87 \%)$. Blood pressure was monitored for majority of women in case group $(91.7 \%)$ and in the control group $(92.6 \%)$. Majority of the women in the case group $(52.8 \%)$ had not received nutritional education whereas in the control group majority $(71.3 \%)$ had received nutritional education. Majority of the subjects in the case group and in the control, group had no history of thyroid disorders $(74.1 \%)$. Majority of the subjects in the case group $(97.2 \%)$ and in the control group $(98.2 \%)$ had no history of renal disease. None of the subjects in the case group and in the control, group had connective tissue disorder. Majority of the subjects in the case group $(93.5 \%)$ and in the control group (97.2\%) had no history of diabetes. Majority of the women in the case group $(75.9 \%)$ and in the control group $(85.2 \%)$ had no family history of diabetes. Most of the women in the case group $(69.4 \%)$ and in the control group $(83.3 \%)$ had no family history of hypertension.

In case of salt consumption, most of the women in the case group and in the control group (47.2\%) consumed 1$2 \mathrm{gm}$ of salt. Majority of the women in the case group $(42.6 \%)$ consumed less than $30 \mathrm{gm}$ of fatty fried food whereas in the control group majority $(35.2 \%)$ consumed more than 30 grams of fatty fried food. Majority of the women in the case group $(41.7 \%)$ and in the control group $(30.6 \%)$ consumed less than 20 grams of processed sugar. Majority of the women in the case group (37\%) consumed $300 \mathrm{ml}$ of milk whereas in the control group majority $(40.7 \%)$ consumed less than $200 \mathrm{ml}$ of milk. Majority of the women in the case group (42.6\%) never consumed green leafy vegetables whereas in the control group majority $(50 \%)$ consumed 1 cup of green leafy vegetables daily. Majority of the women in the case group $(54.6 \%)$ and in the control group (70.4\%) consumed fruits daily. Majority of the women in the case group $(46.3 \%)$ and in the control group (50\%) consumed 40-50 grams of pulses daily. Majority of the women in the case group $(37 \%)$ consumed fish occasionally whereas in the control group majority $(41.7 \%)$ consumed fish weekly. Majority of the women in the case group $(67.6 \%)$ and in the control group $(60.2 \%)$ engaged in moderate activities. None of the women in case and in the control, group engaged in tobacco and alcohol use.

The Table 1 shows that among the socio-demographic variables, only age in years $(\mathrm{p}=0.026)$ and mean age $(p=0.018)$ were found to be statistically significant.

The Table 2 shows that among clinical factors, body mass index $(\mathrm{p}=0.001)$, mean BMI $(\mathrm{p}=0.039)$, mean hemoglobin level $(\mathrm{p}=0.003)$, weeks of gestation $(\mathrm{p}=0.016)$, mean age of menarche $(\mathrm{p}=0.003)$, age at first pregnancy $(\mathrm{p}=0.016)$, mean age at first pregnancy $(\mathrm{p}=0.007)$, nutritional education $(\mathrm{p}=0.001)$, family history of hypertension ( $\mathrm{p}=0.016)$, salt consumption $(\mathrm{p}=0.001)$, fatty fried food consumption $(\mathrm{p}=0.008)$, processed sugar consumption $(\mathrm{p}=0.045)$, intake of green leafy vegetables $(\mathrm{p}=0.001)$, intake of pulses and beans $(\mathrm{p}=0.031)$ and activity $(\mathrm{p}=0.015)$ were found to be statistically significant and other variables did not show any statistically significant association. 
Table 1: Association between socio-demographic variables, preeclampsia and eclampsia among primigravida $(n=216)$.

\begin{tabular}{|llllll|}
\hline Demographic variables & Case & \multicolumn{3}{c}{ Control } \\
& Frequency & \% & Frequency & $\%$ & Statistical significance \\
\hline Age (Years) & & 2.8 & 5 & 4.6 & \\
\hline$\leq 18$ & 3 & 72.2 & 91 & 84.3 & $\chi^{2}=7.269, \mathrm{df}=2$, \\
\hline $19-30$ & 78 & 25 & 12 & 11.1 & p value $=0.026^{*}$ \\
\hline$>30$ & 27 & & 24.6 & & $\begin{array}{l}\mathrm{t}=3.692, \mathrm{df}=214, \\
\mathrm{p} \text { value }=0.018^{*}\end{array}$ \\
\hline Mean age (year) & 27.3 & & & & \\
\hline
\end{tabular}

Table 2: Association between clinical factors and preeclampsia and eclampsia among primigravida $(n=216)$.

\begin{tabular}{|c|c|c|c|c|c|}
\hline \multirow{2}{*}{ Clinical factors } & \multicolumn{2}{|l|}{ Case } & \multicolumn{2}{|l|}{ Control } & \multirow{2}{*}{ Statistical significance } \\
\hline & Frequency & $\%$ & Frequency & $\%$ & \\
\hline \multicolumn{6}{|l|}{ Body mass index } \\
\hline Underweight & 2 & 1.9 & 3 & 2.8 & \multirow{5}{*}{$\begin{array}{l}\chi^{2}=22.2 \\
\mathrm{df}=4, \mathrm{p} \text { value }=0.001 * *\end{array}$} \\
\hline Normal & 26 & 24.1 & 53 & 49.1 & \\
\hline Overweight & 41 & 38 & 38 & 35.2 & \\
\hline Obese & 36 & 33.3 & 14 & 13 & \\
\hline Over obese & 3 & 2.8 & 0 & 0 & \\
\hline Mean HB level & 10.7 & & 10.4 & & $\begin{array}{l}\mathrm{t}=2.278 \\
\mathrm{df}=214, \mathrm{p} \text { value }=0.003^{*}\end{array}$ \\
\hline \multicolumn{5}{|l|}{ Weeks of gestation } & \multirow{4}{*}{$\begin{array}{l}\chi^{2}=5.793 \\
\mathrm{df}=1, \mathrm{p} \text { value }=0.016^{*}\end{array}$} \\
\hline Less than 37 & 80 & 74.1 & 94 & 87 & \\
\hline More than 37 & 28 & 25.9 & 14 & 13 & \\
\hline More than 13 & 59 & 54.6 & 71 & 65.7 & \\
\hline Mean Age at menarche & 13.7 & & 14.0 & & $\begin{array}{l}t=-1.671 \\
d f=214, p \text { value }=0.003^{*}\end{array}$ \\
\hline \multicolumn{5}{|c|}{ Age at first pregnancy (years) } & \multirow{4}{*}{$\begin{array}{l}\chi^{2}=8.24 \\
\mathrm{df}=2, \mathrm{p} \text { value }=0.016^{*}\end{array}$} \\
\hline Less than 20 & 9 & 8.3 & 19 & 17.6 & \\
\hline $21-25$ & 42 & 38.9 & 51 & 47.2 & \\
\hline More than 25 & 57 & 52.8 & 38 & 35.2 & \\
\hline $\begin{array}{l}\text { Mean age at first } \\
\text { pregnancy }\end{array}$ & 27.2 & & 24.4 & & $\begin{array}{l}\mathrm{t}=3.857 \\
\mathrm{df}=214, \mathrm{p} \text { value }=0.007 *\end{array}$ \\
\hline \multicolumn{5}{|c|}{ Nutritional education given } & \multirow{3}{*}{$\begin{array}{l}\chi^{2}=12.963 \\
d f=1, p \text { value }=0.001 * *\end{array}$} \\
\hline Yes & 51 & 47.2 & 77 & 71.3 & \\
\hline No & 57 & 52.8 & 31 & 28.7 & \\
\hline \multicolumn{5}{|c|}{ Family history of hypertension } & \multirow{3}{*}{$\begin{array}{l}\chi^{2}=5.775 \\
\mathrm{df}=1, \mathrm{p} \text { value }=0.016^{*}\end{array}$} \\
\hline Yes & 33 & 30.6 & 18 & 16.7 & \\
\hline No & 75 & 69.4 & 90 & 83.3 & \\
\hline \multicolumn{5}{|c|}{ Family history of diabetes } & \multirow{3}{*}{$\begin{array}{l}\chi^{2}=2.956 \\
\mathrm{df}=1, \mathrm{p} \text { value }=0.086\end{array}$} \\
\hline Yes & 26 & 24.1 & 16 & 14.8 & \\
\hline No & 82 & 75.9 & 92 & 85.2 & \\
\hline \multicolumn{5}{|c|}{ Salt consumption (daily) (gm) } & \multirow{5}{*}{$\begin{array}{l}\chi^{2}=19.8 \\
\mathrm{df}=4, \mathrm{p} \text { value }=0.001 * *\end{array}$} \\
\hline $1-2$ & 51 & 47.2 & 51 & 47.2 & \\
\hline $3-4$ & 33 & 30.6 & 47 & 43.5 & \\
\hline $4-5$ & 19 & 17.6 & 4 & 3.7 & \\
\hline$>5$ & 5 & 4.6 & 6 & 5.6 & \\
\hline \multicolumn{5}{|c|}{ Fatty fried food (daily) (gm) } & \multirow{5}{*}{$\begin{array}{l}\chi^{2}=11.84 \\
d f=3, p \text { value }=0.008^{*}\end{array}$} \\
\hline$<30$ & 46 & 42.6 & 23 & 21.3 & \\
\hline 30 & 20 & 18.5 & 28 & 25.9 & \\
\hline$>30$ & 31 & 28.7 & 38 & 35.2 & \\
\hline Never & 11 & 10.2 & 19 & 17.6 & \\
\hline
\end{tabular}

Continued. 


\begin{tabular}{|c|c|c|c|c|c|}
\hline \multirow{2}{*}{ Clinical factors } & \multicolumn{2}{|l|}{ Case } & \multicolumn{2}{|l|}{ Control } & \multirow{2}{*}{ Statistical significance } \\
\hline & Frequency & $\%$ & Frequency & $\%$ & \\
\hline \multicolumn{5}{|c|}{ Processed sugar (daily) (gm) } & \multirow{5}{*}{$\begin{array}{l}\chi^{2}=8.048 \\
d f=3, p \text { value }=0.045^{*}\end{array}$} \\
\hline$<20$ & 45 & 41.7 & 33 & 30.6 & \\
\hline $20-25$ & 35 & 34.3 & 28 & 25.9 & \\
\hline$>25$ & 14 & 13 & 28 & 25.9 & \\
\hline Never & 14 & 13 & 19 & 17.6 & \\
\hline \multicolumn{5}{|c|}{ Intake of green leafy vegetables (daily) (Cup) } & \multirow{4}{*}{$\begin{array}{l}\chi^{2}=31.46 \\
\mathrm{df}=3, \mathrm{p} \text { value }=0.001^{* *}\end{array}$} \\
\hline 1 & 35 & 32.4 & 54 & 50 & \\
\hline 1.5 & 18 & 16.7 & 27 & 25 & \\
\hline 2 & 9 & 8.3 & 17 & 15.7 & \\
\hline \multicolumn{5}{|c|}{ Intake of pulses and beans (daily) (gm) } & \multirow{5}{*}{$\begin{array}{l}\chi^{2}=8.891 \\
\mathrm{df}=3, \mathrm{p} \text { value }=0.031^{*}\end{array}$} \\
\hline$<40$ & 33 & 30.6 & 41 & 38 & \\
\hline $40-50$ & 50 & 46.3 & 54 & 50 & \\
\hline$>50$ & 5 & 4.6 & 7 & 6.5 & \\
\hline Never & 20 & 18.5 & 6 & 5.6 & \\
\hline \multicolumn{5}{|l|}{ Activity } & \multirow{4}{*}{$\begin{array}{l}\chi^{2}=8.464 \\
\mathrm{df}=2, \mathrm{p} \text { value }=0.015^{*}\end{array}$} \\
\hline Sedentary & 35 & 32.4 & 35 & 32.4 & \\
\hline Moderate & 73 & 67.6 & 65 & 60.2 & \\
\hline Heavy & 0 & 0 & 8 & 7.4 & \\
\hline
\end{tabular}

Table 3: Association between socio-demographic variables and preeclampsia and eclampsia among preeclamptic/eclamptic mothers (multiple logical regression) $(\mathrm{n}=\mathbf{1 0 8})$.

\begin{tabular}{|c|c|c|c|c|}
\hline \multirow{2}{*}{ Demographic variables } & \multicolumn{3}{|c|}{ Preeclampsia and eclampsia } & \multirow{2}{*}{$P$ value } \\
\hline & Frequency & $\%$ & Adjusted OR $95 \%$ (CI) & \\
\hline \multicolumn{5}{|l|}{ Age (years) } \\
\hline$\leq 18$ & 3 & 2.8 & \multirow{3}{*}{$0.973(0.381-2.488)$} & \multirow{3}{*}{0.955} \\
\hline $19-30$ & 78 & 72.2 & & \\
\hline$>30$ & 27 & 25 & & \\
\hline \multicolumn{5}{|l|}{ Place of residence } \\
\hline Urban & 36 & 33.3 & \multirow{3}{*}{$0.965(0.434-2.143)$} & \multirow{3}{*}{0.930} \\
\hline Rural & 72 & 66.7 & & \\
\hline Suburban & 0 & 0 & & \\
\hline \multicolumn{5}{|l|}{ Educational status } \\
\hline Illiterate & 4 & 3.7 & \multirow{5}{*}{$0.713(0.479-1.062)$} & \multirow{5}{*}{0.096} \\
\hline Primary & 28 & 25.9 & & \\
\hline Secondary & 21 & 19.4 & & \\
\hline Graduate & 44 & 40.7 & & \\
\hline Postgraduate & 11 & 10.2 & & \\
\hline \multicolumn{5}{|l|}{ Employment status } \\
\hline Employed & 7 & 6.5 & \multirow{2}{*}{$0.669(0.115-3.896)$} & \multirow[b]{2}{*}{0.654} \\
\hline Unemployed & 101 & 93.5 & & \\
\hline \multicolumn{5}{|l|}{ Type of marriage } \\
\hline Consanguineous & 31 & 28.7 & \multirow{2}{*}{$1.330(0.612-2.892)$} & \multirow{2}{*}{0.472} \\
\hline Non-Consanguineous & 77 & 71.3 & & \\
\hline \multicolumn{5}{|l|}{ Type of family } \\
\hline Nuclear & 61 & 56.5 & \multirow{3}{*}{$0.958(0.488-1.880)$} & \multirow{3}{*}{0.901} \\
\hline Joint & 47 & 43.5 & & \\
\hline Extended & 0 & 0 & & \\
\hline \multicolumn{5}{|l|}{ Monthly income (Rs.) } \\
\hline$<2000$ & 46 & 42.6 & \multirow{4}{*}{$1.070(0.753-1.522)$} & \multirow{4}{*}{0.705} \\
\hline $2000-5000$ & 23 & 21.3 & & \\
\hline $5001-10000$ & 25 & 23.1 & & \\
\hline$>10000$ & 14 & 13 & & \\
\hline
\end{tabular}


Table 4: Association between clinical factors and preeclampsia and eclampsia among preeclamptic/eclamptic mothers (Multiple logistic regression) $(n=108)$.

\begin{tabular}{|c|c|c|c|c|}
\hline \multirow{2}{*}{ Clinical factors } & \multicolumn{3}{|c|}{ Preeclampsia and eclampsia } & \multirow{2}{*}{ P value } \\
\hline & Frequency & (\%) & Adjusted OR 95 \% (CI) & \\
\hline \multicolumn{5}{|l|}{ Body mass index } \\
\hline Underweight & 2 & 1.9 & \multirow{5}{*}{$2.28(1.40-3.71)$} & \multirow{5}{*}{$0.001 * *$} \\
\hline Normal & 26 & 24.1 & & \\
\hline Overweight & 41 & 38 & & \\
\hline Obese & 36 & 33.3 & & \\
\hline Over obese & 3 & 2.8 & & \\
\hline \multicolumn{5}{|l|}{ Thyroid disorder } \\
\hline Yes & 24 & 22.2 & \multirow{2}{*}{$2.756(1.135-6.645)$} & \multirow[b]{2}{*}{$0.025^{*}$} \\
\hline No & 84 & 74.1 & & \\
\hline \multicolumn{5}{|c|}{ Intake of green leafy vegetables (daily) (cup) } \\
\hline 1 & 35 & 32.4 & \multirow{4}{*}{$1.699(1.223-2.360)$} & \multirow{4}{*}{$0.002 *$} \\
\hline 1.5 & 18 & 16.7 & & \\
\hline 2 & 9 & 8.3 & & \\
\hline Never & 46 & 42.6 & & \\
\hline
\end{tabular}

Table 3 shows the association between demographic variables associated with preeclampsia and eclampsia mothers. The demographic variables are not statistically significant to preeclampsia and eclampsia mothers.

Table 4 shows the association between clinical factors associated with preeclampsia and eclampsia mothers. The clinical factors statistically significant were Body mass index $(\mathrm{p}=0.001)$, thyroid disorder $(\mathrm{p}=0.025)$ and Intake of green leafy vegetables $(\mathrm{p}=0.002)$.

\section{DISCUSSION}

The risk factors identified in the study were maternal age, hemoglobin level, BMI, weeks of gestation, age at menarche, age at first pregnancy, nutritional education, history of thyroid disorder, family history of hypertension, salt consumption, consumption of fried fatty food and processed sugar, and intake of green leafy vegetables and pulses and beans and activity. The findings of the study were concurrent with the findings of the researcher who conducted a study to evaluate the risk factors for pre-eclampsia and the factors found were nulliparity, body mass index, hemoglobin and blood Rh, maternal age, gestational age, educational status, contraceptive methods, previous history of preeclampsia, history of preeclampsia in the family, infection of the urinary tract, season during which delivery is conducted and the level of activity. ${ }^{15}$

The study identified maternal age as the only socio demographic variable associated with preeclampsia and eclampsia. The above finding was concordant with the study conducted by Ogawa et al to elucidate the effect of maternal age on pregnancy outcomes and its relationship with parity and contraceptive methods and the study conducted by Kawakita et al to investigate the outcomes of adolescent pregnancy. ${ }^{16,17}$ The study concluded that greater risk for preeclampsia was related to very advance maternal age $(\geq 45)$ and younger adolescents respectively.

The study findings revealed that there is a significant association between risk factor like maternal age, hemoglobin level, BMI, weeks of gestation, age at menarche, age at first pregnancy, nutritional education, history of thyroid disorder, family history of hypertension, activity and between the occurrence of

preeclampsia and eclampsia. The findings of the study were concurrent with the findings of the researcher who conducted a study to identify the risk factors related to preeclampsia and to compare the socio-demographic profile of women with and without preeclampsia and the risk factors identified were increased BMI, young age at menarche, anemia, primiparity, family history of preeclampsia and hypertension and non veg diet. ${ }^{18}$

The study findings revealed that there is a significant association between dietary factors like salt consumption, consumption of fried fatty food and processed sugar, and intake of green leafy vegetables and pulses and beans between the occurrence of preeclampsia and eclampsia. The study findings were consistent with the findings of the study conducted by Grum et al to assess the dietary factors associated with preeclampsia or eclampsia among pregnant women. The dietary factors associated were vegetable and fruit intake during pregnancy and receiving nutritional counseling during antenatal care. ${ }^{19}$ The study findings were also similar with the findings of the study conducted by Frederick et al to find the association between occurrence of preeclampsia and maternal dietary 
intake of micronutrients. The findings of the study showed that there was an inverse relationship between occurrence of preeclampsia and intake of fiber. And the dietary habits which prevented preeclampsia were intake of potassium, calcium and magnesium, consumption of fruits and vegetables, dairy products with low fat, cereal and brown bread. ${ }^{20}$

Body mass index, thyroid disorder and intake of green leafy vegetables were found to be independent risk factors associated with preeclampsia and eclampsia.

Motedayen et al conducted a systematic review and metaanalysis to determine the relationship between body mass index and preeclampsia. The results revealed that there is a significant relationship between BMI and preeclampsia. $^{21}$

Another study conducted by Sardana et al to assess the relationship between thyroid hormone in pregnancy and preeclampsia. The study concluded that identification of changes in thyroid hormones in preeclampsia might be of help in preventing the occurrence of preeclampsia. ${ }^{22}$

A study conducted by Agrawal on frequency of consumption of specific food items and symptoms of preeclampsia and eclampsia identified intake of green leafy vegetables as one of the food items which substantially lowers the risk of preeclampsia and eclampsia. $^{23}$

\section{Assumptions}

The study assumes that the responses given by the study participants are true.

\section{CONCLUSION}

The study concluded that there is a significant risk among women less than 18 years and more than 30 years, women with anemia and obesity, women with week of gestation less than 37 weeks, women with age of menarche less than 13 years, women with age at first pregnancy less than 18 and more than 30, women who have not received any kind of nutritional education, positive family history of hypertension, increased consumption of salt, fatty fried food, processed sugar and decreased intake of green leafy vegetables and pulses and beans have increased risk for preeclampsia that may lead to eclampsia. A format containing all the risk factors should be asked routinely in antenatal checkup to pregnant women to identify the high-risk mothers and to provide them with prompt treatment so as to prevent development of preeclampsia and eclampsia.

\section{ACKNOWLEDGMENTS}

The authors would like to thank all the volunteer subjects who effectively participated in the study. And also,
Jawaharlal institute of medical education and research for giving the permission to conduct the study.

Funding: No funding sources

Conflict of interest: None declared

Ethical approval: The study was approved by the Institutional Ethics Committee (JIP/CON/2019/033)

\section{REFERENCES}

1. Fottrell E, Kanhonou L, Goufodji S, Béhague DP, Marshall T, Patel V et al. Risk of psychological distress following severe obstetric complications in Benin: the role of economics, physical health and spousal abuse. Br J Psychiatry. 2010;196:18-25.

2. Van den Broek NR, Falconer AD. Maternal mortality and Millennium Development Goal 5. Br Med Bull. 2011;99:25-38.

3. Steegers EA, von Dadelszen P, Duvekot JJ, Pijnenborg R. Pre-eclampsia. The Lancet. 2010;376:631-44.

4. Jeyabalan A. Epidemiology of preeclampsia: Impact of obesity. Nutr Rev. 2013;71:18-25

5. Dutta DC. Textbook of Obstetrics. $7^{\text {th }}$ ed. London. New Central Book Agency (P) Ltd. 2011;219-36.

6. Sibai B, Dekker G, Kupferminc M. Preeclampsia. The Lancet. 2005;365:785-99.

7. Registrar General, India, Centre for Global Health Research, University of Toronto, Canada. Maternal mortality in India 1997-2003 Trends, causes and risk factors. New Delhi: Registrar General, India; 2006 Oct. Available from: http://www.health.mp.gov.in/Maternal_Mortali ty_in_India_1997-2003. Accessed on 14/7/2020.

8. Sajith M, Nimbargi V, Modi A, Sumariya R, Pawar A. Incidence of pregnancy induced hypertension and prescription pattern of antihypertensive drugs in pregnancy. Int J Pharm Sci Res. 2014;5:163-70.

9. Agrawal S, Walia G K. Prevalence and risk factors for Preeclampsia in Indian women: a national crosssectional study. J Women's Health. 2014;3:2-9.

10. Bygbjerg IC. Double burden of non-communicable and infectious diseases in developing countries. Science. 2012;337:1499-01.

11. Roberts JM. Medicine-Principles and Practice. Philadelphia: W.B. Saunders. Pregnancyrelated hypertension. 1984:703-52.

12. Lee CJ, Hsieh TT, Chiu TH, Chen KC, Lo LM, Hung TH. Risk factors for pre-eclampsia in an Asian population. Int J Gynaecol Obstet. 2000;70:327-33.

13. Eskenazi B, Fenster L, Sidney S. A multivariate analysis of risk factors for preeclampsia. JAMA. 1991;266:237-41.

14. Mahomed K, Williams MA, Woelk GB, JenkinsWoelk L, Mudzamiri S, Madzime S. Risk factors for preeclampsia-eclampsia among Zimbabwean women: Recurrence risk and familial tendency towards hypertension. J Obstet Gynaecol. 1998; 18:218-22. 
15. Kashanian M, Baradaran HR, Bahasadri S, Alimohammadi R, Razieh. Risk Factors for PreEclampsia: A Study in Tehran, Iran. Arch Iran Med. 2011;14:412-5.

16. Ogawa K, Urayama KY, Tanigaki S, Sago H, Sato S. Association between very advanced maternal age and adverse pregnancy outcomes: a cross sectional Japanese study. BMC Pregnancy Childbirth. 2017; 17:349.

17. Kawakita T, Wilson K, Grantz KL, Landy HJ, Huang CC, Gomez-Lobo V. Adverse Maternal and Neonatal Outcomes in Adolescent Pregnancy. J Pediatr Adolesc Gynecol. 2016;29:130-6.

18. Verma MK, Kapoor P, Yadav R, Manohar RK. Risk Factor Assessment for Preeclampsia: A Case Control Study. Int J Public Health. 2017;7:172-7.

19. Grum T, Hintsa S, Hagos G. Role of nutrition in the risk of preeclampsia. BMC Res Notes. 2018; 11: 683.

20. Frederick IO, Williams MA, Dashow E, Kestin M, Zhang C, Leisenring WM. Dietary fiber, potassium, magnesium and calcium in relation to the risk of preeclampsia. J Reprod Med. 2005;50:332-44.
21. Motedayen M, Rafiei M, Tavirani MR, Sayehmiri K, Dousti $\mathrm{M}$. The relationship between body mass index and preeclampsia: A systematic review and metaanalysis. Int J Reprod BioMed. 2019;17:463-72.

22. Sardana D, Nanda S, Kharb S. Thyroid hormones in pregnancy and preeclampsia. J Turkish-German Gynecol Assoc. 2009;10:168-71.

23. Agrawal S. Frequency of consumption of specific food items and symptoms of preeclampsia and eclampsia in Indian women. Int J Med Public Health. 2014;4:350-53.

Cite this article as: Jaboi RM, Vahitha S., Nivedita. Assessment of socio-demographic and clinical factors associated with preeclampsia and eclampsia among primigravida attending tertiary care center in South India. Int J Reprod Contracept Obstet Gynecol 2020;9:4486-93. 